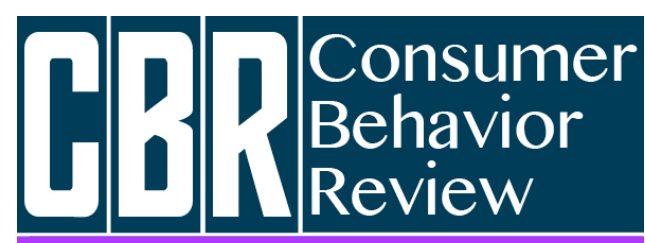

Revista Comportamento do Consumidor
Silva, M. J B., \& Barbosa, M. L. A. (2018). Compartilhando Bicicletas e Consumindo Experiências: uma investigação do consumo colaborativo praticado por usuários do Bike PE. Consumer Behavior Review, 2(Special Edition), 1-18.
ISSN: 2526-7884

Editor: Prof. Dr. Marconi Freitas da Costa

Email da revista: cbr@ufpe.br
Avaliação: Double blind review

Recebido: 16 de maio de 2018

Aceito: 27 de julho de 2018

\title{
Compartilhando Bicicletas e Consumindo Experiências: Uma investigação do consumo colaborativo praticado por usuários do Bike PE
}

\author{
Marianny Jessica de Brito Silva \\ Maria de Lourdes de Azevedo Barbosa
}

Marianny Jessica de Brito Silva é Doutoranda em Administração pelo Programa de Pós-

Graduação em Administração da Universidade Federal de Pernambuco - PROPAD/UFPE. Email: marianny.jbrito@gmail.com

Maria de Lourdes de Azevedo Barbosa é Professora Permanente do Programa de PósGraduação em Administração da Universidade Federal de Pernambuco - PROPAD/UFPE. Email: lourdesbarbosa@gmail.com

Esta pesquisa teve o apoio financeiro da agência de fomento CAPES - Comissão de Aperfeiçoamento de Pessoal do Nível Superior. Os autores agradecem aos avaliadores pelos comentários para melhoria do artigo.

\begin{abstract}
Resumo
O Consumo Colaborativo é uma nova configuração de consumo praticada graças às tecnologias digitais e à possibilidade de acesso que estas proporcionam. Este artigo analisa tal prática, adotando como lócus de pesquisa o Sistema Bike PE, iniciativa de compartilhamento de bicicletas em funcionamento nas cidades de Recife, Jaboatão dos Guararapes e Olinda. A partir de observações e entrevistas individuais com usuários deste serviço, foi possível observar que os consumidores do Bike PE possuem objetivos distintos no uso do sistema e vivenciam diversos problemas no acesso, uso e devolução das bicicletas, mas permanecem utilizando o Bike PE pelas vantagens decorrentes de uma prática colaborativa que traz benefícios coletivos e individuais, como o baixo custo para a utilização da bicicleta, o uso sem preocupações sobre manutenção e segurança, o sentimento de pertencimento à sociedade, a possibilidade de consciência coletiva, sustentabilidade, saúde e, principalmente, a opção de uso sem a necessidade de aquisição.

Palavras-chave: Experiência, Consumo Colaborativo, Bike PE.
\end{abstract}

Esta obra está licenciada com uma Licença Creative Commons Atribuição 4.0 Internacional.

\section{INTRODUÇÃO}

O fenômeno do Consumo Colaborativo (CC) é uma nova forma de comportamento de consumo dirigido pela internet e pela Web 2.0, em que pessoas coordenam a aquisição e distribuição de um recurso (Maya \& Zhai, 2013; Benoit et al., 
2017; Correa et al., 2018). Ele está mudando a forma como as empresas enfrentam suas propostas de valor e como os consumidores satisfazem suas necessidades (Botsman \& Rogers, 2011; Möhlmann, 2015), incentivando redes colaborativas dinamicamente integradas (Figueiredo \& Scaraboto, 2016).

De fato, o intercâmbio coletivo vivenciado nas formas de Consumo Colaborativo fez emergir maneiras distintas de comprar/usar, desenvolvendo debates no campo dos negócios e fazendo surgir empresas envolvidas nesse novo mecanismo de mercado que atualmente são populares, tais como o Uber e o Airbnb (Benoit et al., 2017). Apesar disso, contribuições de pesquisas abordando as configurações do $\mathrm{CC}$ permanecem raras e com numerosas deficiências (Möhlmann, 2015). As diversas definições do tema em questão dificultam ainda mais o estabelecimento de fronteiras teóricas que operacionalizem o Consumo Colaborativo nos estudos do comportamento do consumidor, colocando como sinônimos do termo a economia colaborativa, a partilha ou as redes de colaboração.

Assim, o presente artigo visa observar a evolução da terminologia do Consumo Colaborativo, analisando suas características por meio de uma das práticas do $\mathrm{CC}$; o compartilhamento de bicicletas, forma de transporte que cresce no mundo todo (Botsman \& Rogers, 2011). No Brasil, esta atividade tem sido incentivada pelos governos estaduais, em parceria com empresas privadas, e vem obtendo sucesso (Maya \& Zhai, 2013).

Os projetos de compartilhamento de bicicletas estão presentes em estados como São Paulo, Rio de Janeiro, Bahia e Pernambuco e surgiram como alternativa para a diminuição de frota de veículos e a adoção de práticas mais sustentáveis, sendo parte da transição de mobilidade urbana que está se desdobrando atualmente (Waes et al., 2018). O compartilhamento de bicicletas contribui para uma melhor compreensão do fenômeno Consumo Colaborativo, sendo foco deste estudo o Projeto Bike PE.

Ao propor uma discussão sobre o Consumo Colaborativo, busca-se no plano teórico contribuir para promoção de conhecimento e reflexões sobre um fenômeno atual em suas configurações, rico em suas nuances e único em suas manifestações. Empiricamente, esta pesquisa visa contribuir para o entendimento de uma prática de mercado que traz novas configurações de vivenciar o consumo no cotidiano dos brasileiros.
O artigo é dividido, para além dessa introdução, em duas seções que tratam do Consumo Colaborativo em termos de experiência e conceituações. Posteriormente, a metodologia de pesquisa é descrita, sendo seguida pela análise da experiência dos informantes sobre o Bike PE. Por fim, as considerações finais são desenvolvidas.

\section{A EXPERIÊNCIA DO CONSUMO COLABORATIVO}

O Consumo Colaborativo foi impulsionado pela Era digital, período atual caracterizado pelo desenvolvimento das tecnologias, pela internet e mídias sociais tornadas essenciais na vida das pessoas, fazendo possível interligar-se e propagar ideias de maneira massiva, criando relações virtuais e novas alternativas aos padrões de consumo tradicional (Jorge, Brasil \& Ferreira, 2013, Vaquero \& Calle, 2013), fazendo a conexão entre provedores e consumidores fácil e eficiente (Estelle, 2017). Como reforça Rohden et al. (2014, p. 1), "com o surgimento das tecnologias em rede, o movimento e inovação coletiva advinda dos consumidores vem assumindo novos formatos que modificam a natureza do consumo, o marketing e a própria sociedade".

Além da Era Digital, outros fatos auxiliaram no desenvolvimento do Consumo Colaborativo. Podem ser citados, por exemplo, a sobrecarga econômica e a crise financeira global, as pressões contínuas da escassez de recursos e seu rápido agravamento, a emergente utilização de tecnologias inteligentes e as redes sociais "peer-topeer" (Gansky, 2010; Estelle, 2017). Atrelado a estas motivações, tem-se o chamado de movimento de reurbanização, com pessoas vivendo em casas menores e mais compactas, impossibilitando a propriedade de muitos objetos (carros, máquinas de lavar, secadoras) (Bardhi \& Eckhardt, 2012). A partir deste cenário, o Consumo Colaborativo se desenvolveu e se expandiu, modificando o foco do que as pessoas consomem para como elas consomem; reconhecendo que, nesta Era, as pessoas valorizam mais experiências do que bens (Botsman \& Rogers, 2011; Lang \& Armstrong, 2018). O conceito de experiência é, portanto, central para o Consumo Colaborativo.

Experiências são essencialmente emocionais e pessoais, envolvendo fatores como intepretação pessoal de uma situação a partir de um histórico cultural, de experiências anteriores e de traços da personalidade (Pullman \& Gross, 2003). Compreender o Consumo Colaborativo como uma 
experiência é reiterar que o foco do estudo desta prática está no indivíduo que a consome e não nos atributos daquilo que é consumido.

Apesar das mais diversas práticas colaborativas, todas convergem para um modo de consumo que vai de encontro à posse de algo, que parece ter relação com valores de compartilhamento e sustentabilidade, diminuindo os desperdícios e aumentando a vida útil dos bens (Costa, 2014; Toni, Renzi \& Mattia, 2018). É importante pontuar que, apesar da sustentabilidade não ser o principal objetivo do Consumo Colaborativo, suas práticas, consequentemente, contribuem para menor degradação ambiental e redução da produção de itens novos (Botsman \& Rogers, 2011).

Por ser uma prática recente, o Consumo Colaborativo ainda caminha para uma maturação teórica, necessitando de uma melhor definição das fronteiras relativas às atividades colaborativas, uma vez que seus conceitos são abrangentes, não havendo ainda uma delimitação clara dos elementos que envolvem essa prática de consumo.

\section{O que é o Consumo Colaborativo?}

O termo Consumo Colaborativo surgiu em 1978, a partir da publicação do artigo "Community Structure and Collaborative Consumption: A Routine Activity", de Felson e Spaeth, sendo definido como eventos em que uma ou mais pessoas consomem bens e serviços econômicos a partir de um processo de engajamento em atividades conjuntas com outros indivíduos (Felson \& Spaeth, 1978).

Apesar do seu surgimento ter ocorrido no final dos anos 70, foi a partir de 2000 que o Consumo Colaborativo se tornou mais popular, sendo redefinido por meio da tecnologia e de comunidades entre pares (Botsman \& Rogers, 2011), que facilitaram o contato e a interação entre indivíduos, empresas e grupos de interesse (Sastre \& Ikeda, 2012). Em 2011, o termo passou a ser discutido no meio acadêmico a partir da proposta de Botsman e Rogers (2011), que consideraram o Consumo Colaborativo como uma atividade atraente que aloca necessidades e desejos dos consumidores, envolvendo poucos gastos para estes indivíduos, tendo como exercício a partilha, empréstimos comerciais, alugueis e trocas, geralmente ocorridos ou organizados em plataformas virtuais (Maurer et al., 2012). Nesta definição, quatro princípios são empregados: massa crítica, capacidade ociosa, crença no bem comum e confiança entre estranhos (Botsman \& Rogers, 2011).

As definições de Consumo Colaborativo propostas por Felson e Spaeth (1978) e, posteriormente, por Botsman e Rogers (2011) sofrem críticas de Belk (2014) por suas amplitudes. $\mathrm{O}$ autor considera que ambas abarcam muitas atividades, gerando desordens e questionamentos. Assim, Belk (2014, p. 1579) desenvolve uma nova conceituação para o Consumo Colaborativo, descrevendo-o como "pessoas coordenando a aquisição e distribuição de um recurso por uma pequena quantia ou outra compensação". Belk (2014) ainda aponta que o Consumo Colaborativo é o subconjunto de um consumo maior denominado por Bardhi e Eckhardt (2012) de Consumo baseado no acesso, em que os indivíduos são capazes de acessar bens temporariamente ao invés de comprá-los e possuí-los, podendo ser tal consumo mediado pelo mercado. Com base nessa compreensão, o CC representa uma mudança social e econômica da propriedade para o acesso, conduzindo ao princípio da desmaterialização, em que o consumo gera compartilhamento sem diminuir a satisfação do locatário individual (Maya \& Zhai, 2013).

Em 2015, Hamari et al. (2015, p. 7) desenvolvem uma definição para o Consumo Colaborativo, descrevendo-o como "atividade peer-to-peer de obtenção, doação ou compartilhamento do acesso de bens e serviços, coordenada por meio de serviços online baseados na comunidade". A partir desta percepção, o CC passa a ser caracterizado pelas trocas físicas e digitais e o acesso pela possibilidade de utilizar o bem, podendo existir tanto práticas de transferência de propriedade, representadas pela permuta, doação e compra de bens usados, como atividades baseadas na compreensão de acesso de Bardhi e Eckhardt (2012) e de Belk (2014), descritas como os aluguéis e empréstimos.

A compreensão de Hamari et al. (2015), que também se apoia em Botsman e Rogers (2011), realça que o $\mathrm{CC}$ oferece novas configurações de consumo que podem envolver uma troca efetiva de bens, além da ideia de alugueis e empréstimos. Nesse sentido, o que diferencia o Consumo Colaborativo da abordagem tradicional é que os bens trocados ou comprados já são usados, o que valoriza a sua funcionalidade, em detrimento da aquisição de novos produtos. Nesse caso, geralmente, os próprios consumidores interagem e trocam ou vendem os produtos que possuem, mas também pode haver um mercado como mediador 
(Belk, 2014). Esta prática não deixa de realçar o dinamismo da sociedade atual, pois os indivíduos podem trocar ou vender constantemente seus bens, demonstrando certo desapego as posses.

Levando em conta tais definições, Silva e Barbosa (2016) apresentam algumas características do Consumo Colaborativo, são elas: a) o Consumo Colaborativo é realizado ou organizado em plataformas virtuais; b) é caracterizado pela possibilidade de acesso (disponibilidade de uso) a bens e serviços por meio da colaboração entre consumidores; c) suas práticas maximizam a utilidade do bem; d) ele ocorre mediante uma pequena quantia paga ou outra compensação; e) pode ser totalmente organizado e realizado pelos consumidores ou pode ser mediado pelo mercado; f) é uma alternativa sustentável com pouco ônus para o consumidor e; g) apresenta como atividades os alugueis, empréstimos, permuta, troca e compra de bens e serviços desde que tais práticas sejam detentoras das demais características descritas acima.

Algumas dessas características apontam a existência de uma rede colaborativa de consumo em que há a agregação de esforços dos participantes visando o alcance de objetivos comuns ou compatíveis e a dependência dos participantes para acessar os recursos (Scaraboto, 2015, Figueiredo \& Scaraboto, 2016). O CC é caracterizado, portanto, como relação triádica em que existem: a) um provedor da plataforma de troca, (b) um cliente que procura acesso aos ativos e (c) um provedor de serviço que concede esse acesso (Benoit et al., 2017).

Assim, o Consumo Colaborativo é descrito como atividade realizada por meio da experiência de colaboração entre consumidores, possibilitando o acesso (disponibilidade de uso) a bens e serviços, sendo realizado ou organizado em plataformas virtuais, podendo ser mediado pelo mercado, apresentando como princípios a maximização da utilidade do bem, que gera aspectos de sustentabilidade e o pouco ônus para o consumidor. Tal prática é gerada e gera, ao mesmo tempo, redes colaborativas e funciona a partir da tríade presente nessas teias.

\section{MÉTODO DA PESQUISA}

Esta pesquisa caracteriza-se como de natureza qualitativa, utilizando-se como técnicas de coleta de dados a observação participante e a entrevista individual não estruturada. Foram feitas observações dos consumidores em treze das oitenta plataformas existentes no Recife, Jaboatão e
Olinda, sendo estas as escolhidas em função de sua localização, próximas de universidades e colégios de referência; centros de comércio e shoppings da cidade, além das plataformas localizadas em áreas de lazer e para a prática de exercícios físicos e em pontos turísticos das cidades.

A finalidade da observação derivou da necessidade de uma maior familiarização com esse ambiente, bem como conhecer na prática como usuários acessam as bicicletas, para melhor compreender o contexto desse tipo de consumo. Como não foram encontrados dados relativos ao perfil dos usuários do projeto Bike $\mathrm{PE}$, pelo impedimento de sua divulgação oficial pela gestão do projeto, a observação possibilitou alguma compensação para se conhecer algumas características dos consumidores desse sistema. Ademais, por meio desse contato pessoal com os usuários foi possível marcar algumas entrevistas posteriores.

Para as observações foi elaborado um roteiro com tópicos guia, o que permitiu melhor estruturar os registros das mesmas em um diário de campo, bem como anotar todos os elementos importantes, relativos aos comportamentos dos sujeitos em interação com a plataforma do Bike $\mathrm{PE}$, a relação deles com a bicicleta acessada e a interação entre usuários.

A observação participante permitiu ainda a interação com os usuários quando da retirada ou devolução das bicicletas, bem como durante uso da bicicleta pela pesquisadora, quando foi possível acompanhar alguns usuários em seus trajetos, o que levou à visualização destes indivíduos experienciando $o$ acesso às bicicletas $e$, consequentemente, a forma de relacionamento com um bem público, os cuidados com a plataforma e com a bicicleta e as possíveis dificuldades na utilização deste sistema de compartilhamento.

Em relação às entrevistas individuais e não estruturadas, tiveram como objetivo conhecer mais profundamente a perspectiva dos indivíduos (Patton, 2002) envolvidos com a prática do acesso das bicicletas, a partir de diálogo interativo com foco nos contextos, situações particulares, comportamentos e nuanças (Godoi \& Mattos, 2010), visando melhor compreender a experiência de cada sujeito no contexto do consumo baseado no acesso, por meio do compartilhamento de bicicletas, voltando-se para a profundidade dos significados que emergiram no discurso dos indivíduos em relação às suas práticas. A entrevista não-estruturada contribuiu para uma conversação que valorizou a tomada de consciência do sujeito, 
oferecendo-lhe a possibilidade de construir sua resposta (Mattos, 2005).

Os critérios de escolha dos sujeitos da pesquisa foram: a) ser usuário do projeto Bike $\mathrm{PE} \mathrm{e}, \mathrm{b}$ ) utilizar as bicicletas compartilhadas pelo menos uma vez por semana, caracterizando a adesão efetiva do cliente ao Sistema, obtendo-se o depoimento de 24 informantes. Logo após a finalização das mesmas, ocorreu uma análise preliminar e, ao se constatar que as informações obtidas começavam a se repetir, não apresentando novas evidências, considerou-se encerrada a coleta de dados, utilizando-se o critério de saturação dos dados (Taylor \& Bogdan, 1998). A partir da entrevista 19, tal critério já foi evidenciado, realizando-se ainda mais cinco entrevistas, como critério de qualidade da pesquisa.

$\mathrm{O}$ acesso aos entrevistados foi possível a partir da observação e da técnica da cadeia de informantes, mais conhecida como bola de neve. Uma vez realizadas, as entrevistas foram gravadas por meio de aparelho digital, com a devida autorização dos participantes e, posteriormente, foi realizada a transcrição integral da conversação, apontada por Merriam (1998) como o melhor banco de dados para análise. A partir da coleta por meio das entrevistas e da observação direta, seguiu-se para a análise de dados.

Foi adotada a Análise de Discurso na perspectiva Social-Hermenêutica, também chamada de Análise Sociológica do Discurso, que é uma análise contextual, na qual os argumentos tomam sentido na relação com os autores que os enunciam, onde aspecto pragmático é considerado,

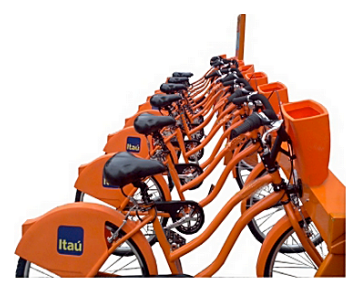

Figura 1: Estações do Bike-PE

Fonte: Bike-PE (2015)

Para a adesão ao Projeto é necessário fazer um cadastro no site e comprar um passe mensal no valor de $\mathrm{R} \$ 10,00$ ou diário no valor de $\mathrm{R} \$ 5,00$, sendo este último disponível diretamente na estação. Há também a possibilidade de acessar as bicicletas a partir do passe VEM, cartão este usado para viagens em transportes públicos urbanos, como ônibus, cabendo não ao usuário, ou seja, aquilo que extrapola a fala (contexto) são fontes de compreensão do discurso (Godoi, 2010). A partir dela, utilizou-se a compreensão pragmática proposta por Mattos (2005), sendo suas etapas compostas pela transcrição e recuperação dos momentos da entrevista; pela análise em si do significado pragmático da conversação que envolve o significado de cada fragmento de texto em três perspectivas: o significado nuclear da resposta (o que foi realmente dito); os significados incidentes (algo mais que pode ser extraído da resposta); e os significados de contexto (suposições implícitas a respeito do contexto relevantes ao tópico) (Mattos, 2005); pela validação das informações centrais; pela montagem da consolidação da fala e; da análise de conjuntos.

\section{Lócus de Pesquisa}

O Bike PE foi desenvolvido a partir de uma parceria entre o governo estadual, as prefeituras das cidades de Recife, Jaboatão e Olinda, o Banco Itaú e as empresas Serttel/Samba, sendo estas últimas responsáveis pera operacionalização do projeto (Bike PE, 2015), visando oferecer aos indivíduos uma alternativa de transporte sustentável de pequeno percurso. O Projeto conta com estações inteligentes (Figura 1) que utilizam energia renovável e são conectadas a uma central de operações via wireless, onde os usuários cadastrados podem retirar, utilizar e devolver uma bicicleta (Figura 2) na mesma ou em outra estação (Bike PE, 2015).

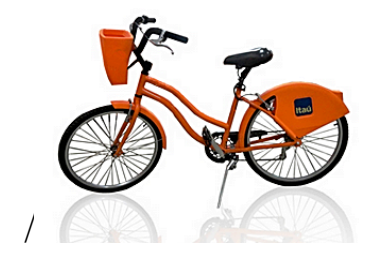

Figura 2: Modelo de bicicleta do Bike-PE

Fonte: Bike-PE (2015)

mas ao governo realizar o pagamento referente à utilização das bicicletas. (Bike PE, 2015). Cada passe dá direito a retirada de uma única bicicleta por vez. Para esta retirada, os usuários podem: a) acionar o aplicativo para smartphone ou realizar uma ligação pelo celular, digitando o número da estação que deseja retirar a bicicleta e o número da posição da mesma ou, b) utilizar o cartão 
VEM, posicionando-o no visor destinado a isto existente diretamente nas plataformas. Quando aparecer a luz verde no local da bicicleta, ela já poderá ser retirada (Bike PE, 2015).

Segundo o termo de adesão do Projeto Bike PE (2015), este sistema de compartilhamento de bicicletas funciona 24 horas por dia e os usuários entendidos como os indivíduos que já realizaram seu cadastro e que compraram o pacote mensal ou diário ou ainda aqueles que cadastraram o Vem no site do projeto - podem realizar viagens gratuitas de até 60 minutos diariamente; após este tempo, eles devem devolver a bicicleta e, após 15 minutos, podem retirar a mesma ou outra.

A partir do aplicativo, baixado gratuitamente em qualquer smartphone, os membros do Bike-PE que realizam o pagamento mensal ou diário podem consultar a situação das plataformas (em operação ou off-line), o número de bicicletas disponíveis na estação desejada, as possíveis vagas nas plataformas para devoluções e podem retirar a bicicleta que desejarem.

Para aqueles que utilizam o Vem, entretanto, não há a possibilidade de observar essas informações, nem tão pouco escolher a bicicleta. Eles apenas passam seus cartões no visor disponível na estação e uma bicicleta é liberada aleatoriamente. Se não houver a devolução da bicicleta em alguma estação dentro do prazo de 60 minutos, será cobrado o valor de $\mathrm{R} \$ 5,00$ por cada hora transcorrida. Caso o equipamento não seja entregue dentro do prazo de um dia subsequente a sua retirada, o consumidor arcará com um valor de R\$ 200,00. Ademais, no caso de danos ocorridos com a bicicleta, o valor do conserto é repassado ao usuário (Bike $\mathrm{PE}, 2015)$.

O Projeto Bike PE tem a adesão de diversos consumidores que haviam realizado mais de 530.000 viagens com as bicicletas até 2015 (Bike PE, 2015) e foi criado com o objetivo de introduzir a bicicleta como modal de transporte público, combater o sedentarismo, reduzir engarrafamentos e a poluição ambiental, promovendo a humanização do ambiente urbano.

\section{Informantes da pesquisa}

Os vinte e quatro entrevistados apresentaram diferentes tempos de adesão ao projeto. Este tempo variou de um mês, representando aqueles clientes novos, até mais de dois anos, sendo estes usuários presentes desde o início da implantação do projeto Bike PE em 2013 (Pernambuco, 2013). A frequência de uso das bicicletas do compartilhamento de Recife também variou entre uma vez por semana, somente aos domingos, até o uso diário (segunda a segunda).

Outra diferenciação observada entre os consumidores do projeto foi a finalidade do uso da bicicleta. Há usuários que acessam o Bike PE com a finalidade da prática de lazer, outros buscam diversão aliada a preocupação com a saúde, realizando exercícios físicos com o uso da bicicleta. Já existem usuários que utilizam a bicicleta como meio de transporte, buscando, alguns deles melhorar a qualidade de vida, praticando exercício físico. Por fim, um informante destaca apenas a questão da saúde, observando o Bike PE como uma prática esportiva.

Esses perfis foram inicialmente identificados nas observações realizadas e, durante as conversações nas estações, os usuários afirmavam que utilizam as bicicletas do projeto para lazer ou para locomoção, ou até para os dois, podendo coexistir a preocupação com a saúde atrelada a uma dessas práticas. A partir dos dados, verificouse que a frequência de uso e a finalidade do acesso às bicicletas do Bike PE são mais intensos de segunda a sexta, como meio de transporte alternativo, sendo nos finais de semana o acesso destas ligado principalmente ao lazer. A distinção da utilidade das bicicletas foi importante, pois algumas diferenciações no discurso dos informantes foram notadas a partir da finalidade de acesso ao projeto. Estas narrativas foram desenvolvidas a partir da conversação com a pesquisadora, sendo suas análises presentes nas seções abaixo.

\section{EXPERIÊNCIA DOS INFORMANTES DO BIKE PE}

Esta seção traz as informações e análises sobre a vivência dos usuários desde a primeira experiência no projeto, a fim de melhor compreender o contexto da prática com o Bike $\mathrm{PE}$, o acesso em si, o que o usuários observam, os problemas enfrentados durante e após o acesso, as vantagens observadas bem como as percepções sobre a ideia da experiência do compartilhamento e a relação com outros usuários do projeto durante os trajetos e/ou na retirada e devolução da bicicleta. Essas categorias emergiram a partir das entrevistas, reforçando o objetivo da pesquisa voltado à compreensão do Consumo Colaborativo a partir do Compartilhamento de Bicicletas.

Antes da análise dos discursos dos entrevistados, a seção seguinte aborda os aspectos 
encontrados a partir da observação participante, demonstrando os resultados em termos de acesso às bicicletas, levando-se em conta a análise das roupas utilizadas, as práticas de retirada, uso ou devolução da bicicleta, os objetivos de uso e o acesso acompanhado ou sozinho a tal sistema.

\section{Impressões iniciais do uso do projeto a partir da observação}

Durante a observação, quarenta e quatro pessoas foram analisadas. A maioria estava utilizando a bicicleta do projeto a lazer (28 usuários); outros estavam a caminho do trabalho, do local de estudo, fazendo desse objeto um meio de transporte alternativo (16 consumidores).

Aqueles que estavam utilizando a bicicleta para lazer estavam com roupas confortáveis ou para específicas para exercício físico realizado em academias. Nenhum deles possuía algum equipamento de proteção, como capacete. Vinte e um destes consumidores estavam acompanhados de outros usuários ou até mesmo de indivíduos com uma bicicleta distinta da disponibilizada pelo sistema, provavelmente de sua propriedade. Nesse caso, observou-se a característica relacional que o projeto oferece para aqueles que utilizam a bicicleta como forma de lazer, reforçando a ideia de rede colaborativa (Scaraboto, 2015; Figueiredo \& Scaraboto, 2016).

A tríade envolvida em atividades de consumo colaborativo (Benoit et al., 2017) foi identificada inicialmente por meio da observação. Há o provedor da plataforma - Itaú - que disponibiliza o acesso ao cliente em busca das bicicletas compartilhadas, obtendo o acesso por meio do serviço prestado pela Serttel e dos outros usuários que devem cuidar e manter as bicicletas em boa conservação a medida que as utilizam.

Os elementos observados por aqueles que estavam retirando a bicicleta eram o painel onde é possível passar o cartão de acesso (Vem) ou então os seus celulares que continham o aplicativo para liberação. Na bicicleta, alguns observaram os pneus. Já aqueles que devolviam, só esperavam o sinal verde presente em cada vaga de bicicleta da estação ascender para irem embora. Ainda na perspectiva do lazer, foi observado que os indivíduos enfrentam problemas para retirada das bicicletas e para devolução. Foi presenciado as tentativas realizadas, por exemplo, de duas usuárias para a retirada da bicicleta.

$\mathrm{O}$ cartão Vem não funcionava, pois o leitor presente na estação informava que não havia bicicleta disponível, mesmo estas estando presentes na plataforma. Depois de algumas vezes tentando passar o cartão, elas desistiram com medo de que este fosse bloqueado. Além disso, a quantidade de vagas disponibilizadas nas estações se mostraram insuficientes para a demanda na devolução do equipamento, principalmente durante a observação na plataforma 03 intitulada Estação Arsenal. Era um dia de domingo e havia muitas pessoas utilizando o projeto nas ruas do Recife Antigo. A pesquisadora vivenciou tal problema, junto a mais seis usuários que tentavam devolver as bicicletas retiradas. A solução foi se locomover o mais rápido possível para outras estações e observar se estas dispunham de vagas, na tentativa de não exceder o tempo de uma hora, previsto para o uso da bicicleta, e pagar a taxa por atraso da entrega.

Os dezesseis usuários observados que acessaram o sistema visando se locomover por meio do modal ciclístico para facilitar a rotina diária e diminuir o tempo com deslocamentos se mostraram mais apressados. As roupas eram variadas, indo desde um calção com uma camisa e um tênis à uma calça e uma camisa social. Geralmente eles estavam indo para o local onde estudam, saindo do trabalho para almoçar ou até mesmo se deslocando de um trabalho para o outro.

Diferentemente daqueles que buscam o lazer, os usuários em questão, mesmo mais apressados, observavam mais a bicicleta no momento da retirada, testando o freio, as marchas, observando os pneus e as correntes, enfim, fazendo uma checagem rápida do objeto que iriam utilizar. Dos dezesseis consumidores, apenas dois estavam acompanhados, apontando inicialmente que tal prática de acesso quando ligada ao uso de locomoção é mais individual. Os problemas vistos durante a observação destes indivíduos foram essencialmente ligados à retirada das bicicletas. Quatro deles não conseguiram utilizar o projeto, pois a estação se encontrava fora do ar e, no caso de dois deles, o cartão do Vem era tido como bloqueado ou sem cadastro. Por meio das entrevistas, tais resultados do exercício da observação foram complementados e aprofundados.

\section{A primeira experiência com o Bike PE}

O Consumo Colaborativo apresenta a ideia de experiência como elemento central de sua 
estrutura (Lang \& Armstrong, 2018). Segundo a P2P Foundantion (2012), tal prática colaborativa é uma experiência econômica que envolve a compra de experiência e não de coisas materiais. Elas são essencialmente emocionais (Pullman \& Gross, 2003), e foram narradas em termos do primeiro acesso ao sistema pelos 24 informantes entrevistados por meio de sensações vividas por eles. Algumas das primeiras experiências descritas pelos informantes foram negativas, como os discursos apresentados no Quadro 1.

Discursos dos informantes

Foi assim, eu achei complicado porque o sistema travava, aí a gente ia devolver e não tinha lugar pra devolver, aí passava o tempo. Porque da primeira vez foi com o passe né, aí quando passava o tempo cobrava (Informante 2).

Foi desastroso, na realidade, porque eu acho que não andava de bicicleta já fazia alguns anos, aí eu peguei ali no centro, não me lembro aonde, acho que foi lá pelo centro. Aí eu fui para o metrô. Aí eu tentei ir pelo metrô, sendo que tipo quando eu era menor, eu andava na rua não tinha tanto carro assim. Aí eu fiquei meio assustado assim com os carros. Tanto que quando eu fui chegando no metrô, eu desci e fui empurrando ela até chegar no lado de lá. Que eu lembro que nem tinha uma próxima do metrô, eu peguei só de afoitice mesmo, só pra passar de um lado pro outro. Foi péssima a experiência (Informante 21).

Aí a primeira vez quando liberou, ela não liberou a bicicleta. Aí eu fiquei puxando, puxando, puxando e nada da bicicleta sair aí foi mostrando que eu já estava usando já. Aí eu fiquei desesperada, "Meu Deus e agora? Vai passar uma hora e o negócio usando". Aí depois eu encerrei o aplicativo, abri de novo aí já mostrou que eu tinha devolvido, aí eu peguei outra. Não tentei mais a mesma, peguei outra. Aí consegui (Informante 23). Fonte: Dados da pesquisa.

Quadro 1: Discursos dos informantes sobre as primeiras experiências negativas

Sentimentos de estresse, frustação, medo e desespero foram apontados para descrever a primeira experiência vivida por estes usuários no acesso à bicicleta. Tais emoções ocorreram mediante problemas existentes no sistema do projeto (informantes 2 e 23), nos equipamentos (entrevistada 2) ou na falta de infraestrutura da cidade de Recife para tal modal gerando insegurança para o ciclista (usuário 21). Os sentimentos negativos vivenciados pelos informantes, entretanto, não foram suficientes para que estes abandonassem o projeto, levantando a hipótese de que outros aspectos influenciaram a continuidade no projeto. Já outros informantes demonstram sentimentos positivos sobre sua primeira experiência (Quadro 2).

Discursos dos informantes

Bem, a minha primeira experiência foi assim, foi legal, porque eu não sabia andar de bicicleta e inclusive era meu sonho andar de bicicleta, porque a minha vida toda eu queria andar de bicicleta, eu via as pessoas andando e eu ficava admirando. Porque eu pedia uma bicicleta pra minha mãe e minha mãe não me dava, porque achava perigosa e enfim, eu fui crescendo e fiquei com aquela vontade. Aí pronto, quando eu passei no vestibular que vim estudar aqui aí eu vi a bike e resolvi fazer o cadastro. E assim, foi a melhor experiência, porque além de aprender a andar de bicicleta, também facilitou a locomoção. Assim, as primeiras vezes foram, foram difíceis, mas foram importantes, porque eu aprendi a andar de bicicleta, não cheguei a levar nenhuma queda, o máximo foi um arranhão [risos] (Informante 11).

Lembro, minha primeira vez que eu utilizei tá aqui. Eu acredito que eu tenha até o vídeo (Sério?). Sério, deixa eu ver se eu encontro aqui [começa a mostrar o vídeo gravado no celular]. Eu estava muito eufórico aí [risos durante todo o vídeo]. Eu mandei pros meus irmãos [vídeo acaba]. Pronto, essa foi minha primeira experiência, realmente eu estava muito eufórico aí [risos]. Foi legal, bem legal (Informante 15).

Lembro. Eu fui na estação, eu estava meio ansioso "eita, espero que não dê nenhum problema" [...] Aí eu estava bastante ansioso, porque eu não sabia se ia funcionar, e no final liberou. Aí eu fiz "eita, funciona". Aí eu dei altos giros com a bicicleta na federal, mas foi só aquele boom inicial. "Eita, uma bicicleta sem me preocupar em ter manutenção nem guardar, deixo lá mesmo". Aí voltei e guardei. Aí depois de quinze minutos eu peguei novamente [risos] e fui até o CAC pra almoçar no RU, foi isso mesmo (Informante 18).

Foi no Marco Zero. Na época era só meia hora, só podia pegar a bike por meia hora, tinha que devolver e quinze minutos. Apesar de tudo, foi uma experiência boa, eu gostei (Informante 20).

Fonte: Dados da pesquisa.

Quadro 2: Discursos dos informantes sobre as primeiras experiências positivas 
A experiência descrita pelo informante 11 foi prazerosa por possibilitar o aprendizado de uma nova prática. Já o entrevistado 15 descreve o primeiro acesso à bicicleta como uma situação eufórica que merecia ser registrada e compartilhada com os demais. A ansiedade para o uso com o projeto também foi revelada por um dentre os informantes (18). Reforça-se assim a importância do projeto em possibilitar o acesso a um bem que está associado às práticas realizadas na infância dos indivíduos ou aos seus sonhos de criança de poder andar de bicicleta, aguçando a memória afetiva de tais usuários. De fato, na Era do Acesso (Rifkin, 2000), as pessoas valorizam as memórias (Gansky, 2010), buscando vivenciar experiências que lhes relembrem bons momentos. Por fim, o informante 20 revelou que a experiência foi positiva, apesar do pouco tempo disponibilizado inicialmente (30 minutos) para o uso da bicicleta. Atualmente, o projeto Bike PE aumentou esse tempo de uso para uma hora seguida (Bike PE, 2015).

O tempo é, inclusive, um aspecto importante na prática do compartilhamento ao compreender que $o$ acesso temporário pode ser uma característica do Consumo Colaborativo (Bardhi \& Eckhardt, 2012; Belk, 2014; Möhlmann, 2015). O tempo com o produto deve ser adequado para que outros possam também utilizar aquilo que é oferecido de modo a alcançar o objetivo desta configuração de consumo. Assim, o usuário do sistema, diferentemente do indivíduo que possui a bicicleta, não tem controle sobre a duração de uso da bicicleta e quem pode ou não utilizá-la (Bardhi \& Eckhardt, 2012). Uma vez vivenciada a primeira experiência, os usuários continuaram a acessar o Bike PE, sendo diferentes os momentos e as formas de acesso, conforme apresentado a seguir.

\section{Momento do acesso e formas do acesso}

Há duas possibilidades de acessar o sistema do Bike PE e retirar as bicicletas, são elas: o aplicativo disponível para download nos smartphones e o passe Vem (Bike PE, 2015). No aplicativo disponível em smartphones, os usuários pagam dez reais mensalmente e podem observar se a estação desejada possui bicicletas disponíveis e escolher qual bicicleta desejam retirar (Bike PE, 2015). Dos vinte e quatro informantes, apenas seis deles utilizam esta possibilidade de acesso, dispondo do aplicativo para retirada e utilização da bicicleta. Quatro destes entrevistados visam primeiramente o lazer, um a locomoção e outro a prática de exercício físico. Aqueles motivados por práticas de diversão parecem, portanto, estar mais dispostos ao pagamento, visto inclusive como simbólico pela informante 1, para poder acessar as bicicletas.

[...] Então 10 reais hoje em dia é um valor simbólico que eles cobram (Informante 1).

Já a segunda opção, o uso do cartão Vem estudantil ou trabalhador, grátis por um ano, é adotada por dezoito informantes. Inicialmente, como revela o usuário 20 na narrativa abaixo, mesmo com o Vem, os usuários pagavam no início do projeto em 2013 uma taxa anual de dez reais, sendo a gratuidade implantada apenas em 2014.

Fiz com o Vem (Na época tu se cadastrava e não pagasse?). Não, na época eu paguei dez reais, passe anual (Mesmo com o Vem?). Mesmo com o Vem (Desde quando está o Vem gratuito, tu lembra?). Ano passado, desde o ano passado que eles abriram exceção pro Vem e também aumentaram o tempo de meia hora pra uma hora (Informante 20).

A preferência do cartão Vem pela maioria dos informantes revela que o aspecto econômico prevalece sobre o aspecto de comodidade. Por não pagarem diretamente pelo acesso (o governo fica encarregado de tal pagamento), os indivíduos que usam o Vem se privam de algumas vantagens que o uso do aplicativo disponibiliza, como por exemplo, a escolha da bicicleta para uso e o conhecimento sobre as estações e bicicletas disponíveis antes da chegada na plataforma. Tal escolha, portanto, revela uma forma de reação às crises financeiras e à sobrecarga econômica vivenciadas (Gansky, 2010; Estelle, 2017) que os levam a optar pela vantagem econômica em detrimento da vantagem de escolha. O informante 2 descreve esta diferenciação.

$\mathrm{Na}$ verdade, quando você usa o aplicativo, você tem como escolher, pelo Vem você não tem como escolher. Aí é na sorte, no Vem é na sorte (No caso, vocês passam no leitor?). É um leitor que tem na plataforma, a gente passa o cartão e libera a bike. (Qualquer uma das bicicletas?) É, a que estiver lá (Informante 2). 
Como narrado acima, no momento do acesso, os informantes que utilizam o Vem passam o cartão no leitor da plataforma e esperam a liberação de uma bicicleta. Ao chegarem à estação, alguns deles não observam a situação destes objetos, como apontado nos discursos presentes no Quadro 3, seja pela impossibilidade de escolher a que estiver em melhor estado (informante 3) ou pela confiança que têm no projeto (informante 9).

\section{Discursos dos informantes}

Eu só coloco lá o cartão na parte que tem apresente seu cartão. Aí passo o cartão, mostra a posição que vai tá liberada, tem até 12 bicicletas, aí eles liberam a bicicleta (Ah, entendi, no caso você não escolhem. A bicicleta já é liberada?). Não, você não tem direito a escolher não, eles que liberam. Aí não adianta olhar antes (Informante 3).

Agora não, eu observava mais. Mais eu tomei bastante confiança assim no sistema sabe, porque até agora, sinceramente, nunca me deu nenhum problema assim (Informante 9).

Fonte: Dados da pesquisa.

Quadro 3: Discursos dos informantes sobre a inobservância do estado das bicicletas

Como revelam Botsman e Rogers (2011), a confiança é um elemento muito importante na prática colaborativa. No Bike PE, tal sentimento auxilia na certeza de que o equipamento compartilhado estará em condições adequadas de uso graças, por exemplo, a manutenção disponibilizada pelo provedor, além do uso correto realizado pelos demais usuários, possibilitando o acesso a um produto em bom estado. Esta é a confiança expressa na narrativa do Informante 9. Ela é central na prática colaborativa que envolve transações econômicas e fortes relacionamentos emocionais online e off-line (Maya \& Zhai, 2013), revelando a agregação de esforços dos participantes visando o alcance de objetivos comuns ou compatíveis e a dependência dos participantes para acessar os recursos (Scaraboto, 2015, Figueiredo \& Scaraboto, 2016). Alguns outros usuários do Bike PE que acessam o sistema por meio do Vem não apresentam tal confiança. Eles observam se o painel da estação está funcionando e/ou qual a condição de uso da bicicleta que é liberada pelo Bike PE, como demonstrado no Quadro 4.

Discursos dos informantes

Geralmente, sim. Se o pneu está em boas condições pra não me responsabilizar depois (Informante 5).

Então eu vou ao negócio passar o cartão, passo o cartão lá. Quando ele avisa qual que saiu, eu tento fazer uma checagem rápida dela, de apertar os pneus da frente, vê se tá com freio e se a sela dá pra mexer. Geralmente da sela não dá tempo de fazer, porque é tudo muito rápido, mas principalmente eu vejo se tá com freio e se tá com o pneu cheio, porque eu já passei por todo tipo de defeito da bicicleta. Eu acho que no final das contas, essas são as mais relevantes (Informante 6).

Eu observo só se o painel tá ok, mais ou menos isso, porque a gente não pode escolher qual a bicicleta vai pegar. E a que ele liberar, se eu perceber que a bicicleta tá ruim, eu devolvo na hora. Espero dá um tempinho pra liberar outra (Informante 14).

Fonte: Dados da pesquisa.

Quadro 4: Discursos dos informantes sobre a observância do estado das bicicletas

Foi percebido que há uma preocupação com o estado da bicicleta, uma vez que os usuários, ao descobrirem aquela a ser liberada pelo sistema, fazem uma checagem na mesma, observando os pneus, a sela e os freios. A checagem surge como uma medida para evitar ou diminuir a probabilidade de vivenciarem problemas, não querendo ser vistos como responsáveis por tais defeitos, havendo a possibilidade de, caso a bicicleta apresente alguma falha, devolvê-la e tentar a retirada de outra. Outro aspecto analisado é que existe uma pressa em meio a esta checagem, como descreve o informante 6 , usuário do projeto com fins de locomoção. Assim como visto na prática da observação, os consumidores do Bike PE que acessavam as bicicletas para este fim analisavam rapidamente $\mathrm{o}$ estado desta. Tal momento de análise é reduzido, pois geralmente a bike é utilizada como meio de transporte para se chegar a outro compromisso com horário estipulado, não podendo haver atrasos. A isto, reforça-se que o uso desta como modal já é 
voltado para um trajeto mais rápido, evitando desperdício de tempo, sendo parte da transição de mobilidade urbana (Waes et al., 2018).

Os usuários que acessam o projeto por meio do aplicativo digitam o número do celular e a senha registrada no cadastro. A partir disto, estão conectados ao sistema, bastando colocar o número da estação que desejam acessar e, ao aparecer as opções disponíveis, digitar o número da bicicleta que pretendem retirar. A informante 1 descreve tais etapas.

[...] Aí dessa vez que eu comecei mesmo a usar todo dia, eu tive a sorte de encontrar uma pessoa que tava tirando. Aí ele puxou assunto comigo, aí eu disse é a minha primeira vez. Aí ele foi super solícito e me ensinou tudo o que ele fazia. Ele disse "não, olhe, antes de você tirar a bicicleta, você confira se o pneu tá baixo, se a sela você pode regular, se a corrente tá no lugar", ele me ensinou, olhe pra e essas três, quatro coisas, escolha sua bicicleta e retire. Aí como é que eu faço, Eu chego na estação, acesso o aplicativo pela internet, coloco o número da estação. Aí ele reconhece e diz quais são as bicicletas disponíveis. Aí eu escolho uma, observo a bicicleta antes de retirar e escolho e retiro (Informante 1).

A informante 1 revela que há a observação do estado da bicicleta, ensinamento este adquirido por meio da interação com outro usuário, confirmando que as práticas colaborativas proporcionam não só o consumo em si, mas a colaboração entre os pares (Jorge, Brasil \& Ferreira, 2013; Vaquero \& Calle, 2013; Hamari et al., 2015).

A principal diferença observada no acesso das bicicletas em relação aos detentores do Vem e os do aplicativo é que estes últimos analisam o objeto antes da escolha. No caso dos consumidores que acessam por meio do cartão Vem, a análise só é possível após a escolha da bicicleta por parte do sistema. A informante 1 já reforça tal diferenciação e a narrativa abaixo realizada pelo informante 7 corrobora para esta afirmação.
[...] Quando você pega a bicicleta pelo app, você tem a opção de escolher a bicicleta, porque o app disponibiliza lá o número das bicicletas que estão disponíveis. Como agora eu uso pelo app, eu já faço isso antes. Eu vejo qual bicicleta tá mais legal, olho o pneu, vejo o freio como é que tá e só depois que eu acesso o app é que eu já escolho aquela bicicleta, porque já faz uma escolha mais certa (Informante 7).

O uso do aplicativo oferece, de fato, algumas vantagens em comparação ao cartão Vem. A possibilidade de escolha economiza tempo e satisfaz os consumidores ao oferecer-lhes a possibilidade de usar a bicicleta que escolheram. De maneira geral, independentemente do acesso com o Vem ou com o aplicativo, há uma checagem das condições da bicicleta, seja esta análise realizada antes ou após a escolha. Esta preocupação está associada aos problemas vivenciados pelos usuários durante a prática colaborativa em questão. Tais problemáticas são analisadas na próxima seção.

\section{Problemas e vantagens do projeto}

Durante a prática de observação, alguns problemas vivenciados pelos usuários do projeto Bike PE já foram evidenciados, sendo estes reforçados e aprofundados durante as entrevistas. Os problemas citados pelos informantes foram a falta de estações suficientes ou até mesmo de vagas disponíveis nestas para retirada ou devolução da bicicleta (informantes 9 e 18), o próprio sistema do projeto que pode se encontrar fora de comunicação (usuário 3), não reconhecer as bicicletas que estão disponíveis na plataforma (entrevistado 12) ou ainda não reconhecer que houve a devolução do objeto, bloqueando o Vem dos usuários e gerando taxas para o consumidor pagar pela "não-entrega" (informante 15). Ademais, há problemas pelo próprio defeito de algumas bicicletas (entrevistado 4) e da falta de estrutura da cidade de Recife em termos de disponibilizar ciclofaixas (informante 2). Tais problemas são descritos nos discursos do Quadro 5

Discursos dos informantes

Eu acho que o único problema que eu enfrento é de estação, porque as estações que eu vou são muito lotadas, aí eu tenho que ir pra outras pra poder encontrar um lugar disponível, pra poder deixar (Informante 9).

A demanda, embora não tenha muitas pessoas usando, já é grande pra a pouca quantidade de plataforma, de estações (Informante 18). 
Tem vezes que eu fico chateado, porque tem vezes que eu chego lá e o sistema tá sem comunicação, aí isso é uma complicação, porque às vezes você tem que ir, tem que procurar outra estação [...] (Informante 3).

O problema é que cai, cai muito. Tipo, a estação tem bicicleta, não tem como tirar a bicicleta, porque ele diz que não tem bicicleta, como assim? (Informante 12)

Pronto, eu acredito que uma falha muito forte nele é justamente essa falta de conectividade entre a plataforma e a central deles, ou seja, você colocar a bike, a bicicleta e ela não ser reconhecida no sistema, isso aí tá sendo muito frequente. Isso acaba prejudicando o usuário que utiliza diariamente. Por que? O bloqueio dele tipo, uma vez me custou quinze dias o bloqueio, só não foi mais dias porque eu percebi que não estava algo certo e fiquei insistindo pra eles regularizarem essa situação. Aí o que foi que eu fui forçado a fazer? Minha namorada estava com o cartão Vem trabalhador em casa, aí eu fiz o cadastro pra ela. Aí eu tenho o meu e uma redundância que é o dela. Ou seja, se o meu dá errado, eu tenho o dela. Inclusive aconteceu isso na semana passada. O meu cartão foi bloqueado justamente por essa falha de sistema e eu tô utilizando o dela. Já que é um uso frequente meu e eu tenho essa necessidade de locomoção ali dentro do centro, foi algo que eu utilizei como, foi uma medida pra não ficar sem o serviço em caso de falha do sistema (Informante 15).

O serviço do Bike PE é péssimo. Em relação, primeira a algumas bicicletas, assim o pneu murcho, sem o retrovisor, o retrovisor arrancado, as marchas desreguladas, o assento já aconteceu de eu regular e eu ir andando e ele ir descendo, tem uma série de problemas com a bicicleta e também no sistema do Bike PE (Informante 4).

As desvantagens são aquelas que te falei, dos problemas com o sistema e também do fato de não ter ciclofaixa aqui né. Eu só me sinto segura quando tem ciclofaixa, então eu ando no domingo que tem ciclofaixa ou quando é feriado. Se for sem ciclofaixa, não me arrisco não (Informante 2).

Fonte: Dados da pesquisa.

Quadro 5: Discursos dos informantes sobre os problemas do Bike PE

O problema da quantidade insuficiente de estações e/ou vagas presentes nesta para retirada e devolução das bicicletas representa uma deficiência do princípio da massa crítica neste tipo de Consumo Colaborativo. Botsman e Rogers (2011) apontam que tal critério corresponde à quantidade suficiente de elementos para tornar o sistema autossuficiente. No caso do projeto Bike $\mathrm{PE}$, as estações e quantidade de vagas disponíveis em cada uma delas se mostram insuficientes, dificultando a atração e a escolha pela prática de compartilhamento, além de atrapalhar etapas que antecedem ou sucedem o uso, gerando estresse em uma atividade que deveria ser voltada para o lazer e/ou a fuga do estresse do trânsito. No caso daqueles que usam para locomoção, principalmente (entrevistado 11), tal problema incorre em atrasos em compromissos e atividades do dia-a-dia.

Outro problema também é quando as estações estão cheias, aí você tem que ir procurar outra estação pra devolver a bicicleta né ( $E$ às vezes o tempo?). Pois é, às vezes a gente tá em cima da hora, tem algum compromisso, alguma aula que acaba chegando atrasado, perde tempo e chega atrasado. Eles deveriam fiscalizar com maior atenção, mais vezes (Informante 11).

Já problemas com o sistema dificultam o acesso ao serviço de compartilhamento de bicicletas, indo de encontro com a ideia de facilidade e simplicidade que as tecnologias oferecem a fim de incentivar novas formas de consumo (Vaquero \& Calle, 2013; Estelle, 2017). Os informantes algumas vezes, inclusive, desistem de utilizar o projeto no momento que desejam, uma vez que realizam inúmeras tentativas frustrantes de retirar a bicicleta. Esta situação torna-se ainda mais estressante para indivíduos que necessitam acessar o sistema todos os dias, como descrito pelo informante 15 no Quadro 5.

Para que o uso desta prática colaborativa seja efetiva e influencie os indivíduos a utilizarem a bicicleta mais ativamente, é necessário que o projeto melhore e ofereça acesso rápido, um sistema que facilite o uso e não o dificulte, além de bicicletas e estações suficientes e em bom estado. Os problemas desestimulam o acesso entendido, neste contexto, como a prática do pedalar a partir da experiência do uso possibilitada pelo Bike PE - fazendo com que o Consumo Colaborativo, descrito como meio atraente de atender as necessidades dos consumidores (Botsman \& Rogers, 2011, Möhlmann, 2015), não seja tão estimulante no caso do Bike PE quando se observa os problemas vivenciados. Ademais, a ciclofaixa é um elemento importante para o uso da bicicleta, sendo, por exemplo, o uso da bicicleta pela informante 2 condicionado à existência desta. Tal elemento é essencial para a confiança dos usuários durante $o$ uso das bicicletas, além de necessário para que o 
sistema adquira de fato o critério de massa crítica presente na teorização sobre o Consumo Colaborativo. Percebe-se, portanto, que dois elementos do princípios centrais para 0 funcionamento do $\mathrm{CC}$, de acordo com Botsman e Rogers (2011), faltam ao Bike PE, são eles: a massa crítica e a confiança. Apesar dos problemas descritos pelos informantes sobre o projeto Bike $\mathrm{PE}$, estes continuam a utilizá-lo. Existem, portanto, vantagens que fazem com que os usuários se mantenham neste tipo de compartilhamento. Esta seção traz a análise destas vantagens de acordo com a narrativa dos entrevistados.

Alguns deles elogiaram a ideia do projeto em si, de possibilitar o acesso sem a necessidade da posse, levando em consideração os benefícios de tal prática em detrimento da propriedade. É o que realçam os informantes 5,10 e 18 por meio de seus discursos apresentados no Quadro 6.

Discursos dos informantes

Eu acho que o que é bom desse projeto é a parte de poder ter um meio, pra quem não tem bicicleta, de utilizar, juntar amigos e sair, não ficar em casa só as redes sociais usando a internet em casa (Entrevistada 5).

Vale a pena. Vale a pena, porque eu faço as minhas pedaladas sem grandes preocupações. Vou até um destino, paro, dou um tempo e tá lá, tá entregue. Quando eu preciso pego de novo e isso aí, não fico com aquele cuidado né, não tenho que ficar olhando se todos vão roubar, se não vão roubar, entreguei a bicicleta, botei na estação, pra mim vale a pena (Informante 10).

Com certeza, é muito válido. Sempre é válido você oferecer ao usuário um uso compartilhado, isso inclusive também, penso eu, estimula a consciência de coletivo. Por mais que tenha problemas, eles sempre vão surgir, até por ser também um projeto muito novo, numa situação de feedback, mas eu acho que sim. Acho válido [...].Ele estimula o pensamento coletivo de que eu vou preservar esse bem, porque outra pessoa vai usar/ eu também talvez use no futuro, preservar as estações também [...] Então isso é muito bom pras pessoas que querem fazer exercício físico também, pessoas de idade, também é válido, você não tem que ter aquele bem na sua casa, você não tem que ter a manutenção daquele bem na sua casa, tem pessoas que não tem nem onde colocar, moram num apartamento, não tem lugar embaixo pra guardar, não vai querer gastar com corrente e etc, não tem que botar em cima (Informante 18).

Fonte: Dados da pesquisa.

Quadro 6: Discursos dos informantes sobre as vantagens do Bike PE.

De fato, o Consumo Colaborativo surge como uma possibilidade de oferecer acesso aos indivíduos sem que esses tenham a necessidade de possuir o bem acessado (Belk, 2014, Bardhi \& Eckhardt, 2012, Hamari et al., 2015). Por meio do projeto Bike $\mathrm{PE}$, os usuários utilizam as bicicletas sem precisar adquiri-las; tal prática possibilita aos usuários uma interação e socialização com os demais ciclistas reforçando o aspecto da experiência colaborativa descrita por Hamari et al.(2015), além de uma pedalada sem grandes preocupações com a manutenção e com o local adequado para deixar a bicicleta, além de estimular a consciência coletiva. Esta consciência é apontada por Botsman e Rogers (2011) como a crença no bem comum, um dos princípios do Consumo Colaborativo. Os usuários passam a compreender que certos bens podem ser úteis para todos, de modo que haja a colaboração entre os pares no uso e compartilhamento correto do que é compartilhado (Jorge, Brasil \& Ferreira, 2013, Vaquero \& Calle, 2013, Estelle, 2017). Ainda destaca-se o elemento da reurbanização (Bardhi \& Eckhardt, 2012) na fala do informante 18, revelando que é vantajoso o acesso à bicicleta para aquelas pessoas que não possuem espaço em suas casas para guardar este objeto. $\mathrm{O}$ projeto ainda pode auxiliar na melhoria da qualidade de vida e na diminuição da poluição urbana, havendo também uma economia de tempo (Waes et al., 2018).

Vale, vale muito a pena porque no meu caso eu utilizo pra locomoção e pra exercício físico, pra trazer uma melhor qualidade de vida. E assim, facilita e muito minha vida. Muitas vezes eu saio em cima da hora, pego a bicicleta e em dois minutos eu chego em algum lugar que eu desejava. E assim facilita muito, traz uma melhor qualidade de vida, praticar exercício, um movimento pra o organismo, os benefícios são show de bola né, e também pra pessoas que só utilizam o carro, moto, que tem o seu meio de locomoção próprio e diminui o impacto no meio ambiente, emissão de $\mathrm{CO} 2$, desses gases e até pelo trânsito também, diminui o trânsito. Não ajuda a piorar ainda mais e pelo que eu vi, vez ou outra eu entro no site na internet, e eu sempre vejo que têm um numerozinho de 
redução dos gases né. E assim, é um projeto fantástico, que eu acredito que deveriam existir mais estações, mais investimento nesse projeto pra que mais pessoas possam aderir, ter uma melhor qualidade de vida, ter facilidade de locomoção, de acesso aos lugares e, enfim, diminuir os impactos na natureza (Informante 11).

Apesar de não ser a principal finalidade do Consumo Colaborativo, suas práticas possibilitam uma menor degradação do meio ambiente (Botsman \& Rogers, 2011; Costa, 2014; Toni, Renzi \& Mattia, 2018). Tal elemento é percebido pelo informante 11, trazendo junto consigo o aspecto social da sustentabilidade ligado à saúde e qualidade de vida da população (Sachs, 2002). A capacidade da bicicleta se apresentar como modal rápido mediante os engarrafamentos também é apontado pelo entrevistado 11 como vantagem, fazendo-lhe poupar tempo para chegar aos lugares.

Por fim, alguns usuários apontam que o projeto apresenta vantagens para aqueles que o utilizam com o intuito de lazer. É o caso da informante 1.

$\mathrm{Eu}$ acho que primeiro um lazer gratuito, porque dez reais pro custo de vida que hoje você tem, que vai pro shopping, pro cinema e paga cinema, paga estacionamento, então a todo momento a sua vida você tá a todo momento sendo cobrada alguma taxa. Então até se você se deslocar, tem lugares que você vai pagar um pedágio, Se você for pro Paiva, lá perto de Recife, você paga pedágio. Então dez reais hoje em dia é um valor simbólico que eles cobram. E é justamente isso, um lazer, você vai ter contato com a natureza, ou o que restou dela, num espaço público, com segurança, pelo menos lá na orla é seguro, com um sistema que funciona e você tem boas bicicletas, porque até agora eu não peguei uma bicicleta que eu cai, que a corrente quebrou. É uma realidade que você não vê aqui no Brasil. $O$ tanto que eu pensava que não funcionava essas coisas (Informante 1).

Como revela a informante $1, \quad \mathrm{o}$ projeto possibilita o uso a lazer por uma taxa simbólica, funcionando em uma realidade contrária a sua existência, devido à cultura de não cuidado com o bem público. De fato, os outros informantes também apontam que o projeto é vantajoso por possibilitar uma prática de lazer ao ar livre, geralmente próxima de áreas culturais, surgindo como forma de interligar os indivíduos à história da cidade. Os problemas são, portanto, amenizados pelos benefícios da prática de compartilhamento e as vantagens que esta traz, elencando vantagens individuais e também coletivas. Outro aspecto também auxilia na superação das problemáticas, descrito como a relação entre os usuários.

\section{Relação entre usuários}

Durante seus acessos ao projeto Bike PE, os usuários podem interagir ou não com demais consumidores desta prática. Assim como identificado nas observações, os informantes que utilizam o Bike PE a lazer demonstraram em seus discursos que existe uma interação com outros usuários durante o uso, seja por meio de conversas rápidas e cumprimentos ao longo do trajeto e estações ou até mesmo por realizarem seus passeios na maioria das vezes acompanhados (alguns deles anseiam por companhia). Tais discursos são vistos no Quadro 7.

\section{Discursos dos informantes}

Tipo, as pessoas são bem sociáveis. Eu não sei se é porque estão em um praça de lazer ou porque estão compartilhando algo, já tem ali uma coisa em comum, que é o compartilhamento da bicicleta. Eu sei que é assim, por exemplo, quando eu tô com algum problema, num instante para uma pessoa pra dizer "ah, como é que está sua bicicleta?". Eu estava sozinha e uma pessoa veio falar comigo quando eu estava usando pela primeira vez, "ah, é a sua primeira vez? Deixa eu te ensinar." Pronto, foi o senhorzinho (Informante 1).

Sempre vou com amigos. Nunca fui sozinha (Informante 2).

Sim, a gente sempre está em grupo, trio, quarteto [...].É porque final de semana na região que a gente mora é perigoso, é muito esquisito (Informante 13).

Fonte: Dados da pesquisa.

Quadro 7: Discursos dos informantes à lazer sobre a relação com outros usuários

Estes indivíduos utilizam o Bike PE quando estão acompanhados. Assim, o pedalar é fundamentalmente social, coletivo e voltado para interação na percepção destes indivíduos. A insegurança em tal prática influencia tal característica (entrevistado 13). É reforçada nesta 
compreensão a existência da colaboração entre os pares descrita como prática do Consumo Colaborativo (Jorge, Brasil \& Ferreira, 2013; Vaquero \& Calle, 2013; Hamari et al., 2015, Scaraboto, 2015; Figueiredo \& Scaraboto, 2016). A lazer, a bicicleta do Bike PE representa, portanto, uma ferramenta de socialização com os demais usuários, reforçando o aspecto de colaboração no conceito de $\mathrm{CC}$ proposto por Hamari et al. (2015). No caso daqueles que têm como finalidade principal a locomoção, o uso em si da bicicleta é uma atividade mais solitária. É o que pode ser observado no Quadro 8.

\begin{tabular}{l}
\hline Discursos dos informantes \\
(Tu nos teus trajetos conversa com algum usuário?) Não, não, não, é muito raro. Às vezes é um \\
cumprimento assim, mas não é nem por ser do projeto, é por ser ciclista (Informante 8). \\
\hline Eu ia citar um caso assim isolado, mas geralmente uso sozinho. É uma situação que eu uso ele pra ir pra \\
um local, rapidamente e voltar. É pontual no meu dia? É, mas se repete bastante, mas é pontual. "Eita, vou \\
correr pra almoçar", se eu viesse a pé eu demoraria 20 minutos, de bicicleta eu tiro cinco minutos. Então eu \\
vou sozinho, embora o uso dela também propicia o uso coletivo. Minha família quer andar de forma coletiva \\
assim, a gente fez o cadastro todo mundo, mas é complicado de achar tanto achar quatro lá quanto voltar e achar \\
as quatro num mesmo canto (Informante 18).
\end{tabular}

Fonte: Dados da pesquisa.

Quadro 8: Informantes que utilizam a bicicleta para locomoção sobre a relação com outros usuários

O que é entendido de maneira geral é que pode haver uma interação durante o uso do projeto por tais usuários, mas este contato é pontual. Compreende-se, de fato, que estar acompanhado não é condição necessária para que estes indivíduos acessem e utilizem as bicicletas. O informante 8, por exemplo, tem contatos, mesmo que raros, com ciclistas e não apenas usuários do Bike PE, por existir um sentimento de pertencimento ao grupo devido as mesmas situações vivenciadas nas ruas de Recife.

Tal realidade pode estar atrelada a afirmativa do informante 18 de que tal transporte é utilizado rapidamente como meio para chegar aos destinos. Reforça-se nesta compreensão que para locomoção, assim como identificado por meio da observação, a bicicleta é um meio e não um fim em si mesma. Desta maneira, é compreendido que a finalidade do uso da bicicleta influencia na necessidade ou não de realizar tal atividade acompanhado. Para lazer, por exemplo, existe uma maior preocupação em vivenciar a experiência em conjunto, fazendo-a um divertimento coletivo e mais seguro.

Para locomoção, o estar acompanhado não é condição necessária; trata-se, portanto, de uma atividade mais solitária. É importante pontuar que solitária não significa individualidade. Como já demonstrado, inclusive, o uso do Bike PE para locomoção está associado ao coletivo, apontando tal atividade de compartilhamento como prática de colaboração que a encaixa na conceituação de
Consumo Colaborativo proposta por Hamari et al. (2015).

\section{CONSIDERAÇÕES FINAIS}

Os resultados demonstraram a importância de refletir sobre as possíveis contribuições desta pesquisa para o mercado, para os gestores do projeto Bike PE e para os próprios consumidores deste tipo de serviço. O sistema de compartilhamento de bicicletas em questão apresenta uma demanda considerável, sendo visto, diante dos resultados analisados, como uma prática que chama a atenção dos consumidores e os incentivam a utilizá-la.

Apesar da motivação por experimentar uma nova configuração de consumo, os usuários do projeto vivenciam problemas que os levam a situações de estresse e de aborrecimento. Essa realidade foi verificada por meio dos discursos dos informantes e das observações. Para os gestores do sistema, se faz necessária uma reavaliação do Bike $\mathrm{PE}$ em termos de conectividade, de modo a facilitar o acesso e o uso a partir de um software capaz de atender os pedidos de retirada e registrar as devoluções. É preciso ainda disponibilizar estações e bicicletas suficientes para atender a demanda, levando em consideração o oferecimento de uma manutenção satisfatória e diária destes aparelhos, a fim de alcançar maior confiança de seus clientes. Além disto, o maior obstáculo a ser transposto é a falta de infraestrutura das próprias cidades em termos de ciclofaixa. Tal realidade inibe o uso contínuo 
das bicicletas durante a semana, desencorajando possíveis consumidores do projeto. Por isso, para que o Bike PE permaneça por mais tempo e atenda satisfatoriamente seus clientes, é preciso uma ação conjunta entre Itaú, Serttel e as prefeituras de Recife, Jaboatão e Olinda a fim de promover o acesso de um bem dispondo da condições indispensáveis para utilizá-lo.

Apesar dos problemas supracitados, o sistema de compartilhamento de bicicletas se mostrou uma oportunidade para o indivíduo desfrutar de um bem sem necessitar adquiri-lo, dando-lhe mais opções em termos de configurações de consumo a ser praticada. Mas mais do que é isso, o Bike PE, por meio da bicicleta e do pedalar, foi entendido como um meio do consumidor socializar e refletir sobre elementos de coletivismo e cidadania. Tal atividade gerou uma consciência do espaço do outro, do respeito ao pedestre e aos outros motoristas, além de incentivar o pensamento crítico perante as dificuldades enfrentadas no trânsito das cidades.

No âmbito acadêmico, este artigo contribuiu no desenvolvimento de reflexões acerca de uma temática atual que carece de mais estudos. Muito se fala sobre a alternativa de viver sem possuir bens, tendo no compartilhamento a atividade para o alcance desta realidade. Entretanto, ao colocar acesso e propriedade em lados opostos, a complementariedade de ambos se esvai, impossibilitando uma reflexão profunda orientada à compreensão de cada um destes fenômenos e seus impactos no cotidiano dos indivíduos. Assim, é importante considerar o Consumo Colaborativo como prática que envolve ambos os elementos, organizada e/ou praticada em plataformas virtuais, que tem como elemento central a colaboração entre os consumidores, estando estes dispostos a alugar e emprestar, mas também comprar, vender e trocar os bens. Por isso, pesquisas que abordem o CC como constructo, fortalecendo sua conceituação e trazendo contribuições práticas para as atividades nele incluídas são encorajadas e necessárias.

\section{REFERENCES}

Amaro, L., Meira, S., Camargo, \& Slongo, L. (2008). Em que posso ajudar? O varejo e os portadores de deficiência visual. Revista Negócios e Talentos, 5,5-21.
Bardhi, F. \& Eckhardt, G. (2012). Access-based consumption: the case of car sharing. Journal of Consumer Research, (39), 1-18.

Belk, R. W. (2014). You are what you can access: Sharing and collaborative consumption online. Journal of Business Research, (67), 1595-1600.

Benoit, S., Baker, T., Bolton, R., Gruber, T., \&, Kandampully, J. (2017). . A triadic framework for collaborative consumption (CC): Motives, activities and resources \& capabilities of actors. Journal of Business Research, 219-227.

Bike PE. Bike PE Pernambuco. Disponível em: < http://www.bikepe.com.br/>. Acesso em: 25 fev. 2015.

Botsman, R. \& Rogers, R. (2011). O que é meu é seu: como o consumo colaborativo vai mudar o nosso mundo. Porto Alegre: Bookman.

Correa, J., Garzón, W., Brooker, P., Sakarkar, G., Carranza, S., Yunado, L., \& Rincón, A. (2018). Evaluation of collaborative consumption of food delivery services through web mining techniques. Journal of Retailing and Consumer Services. In press.

Costa, R. B. (2014). Entre resistências e dádivas: reflexões sobre o consumo colaborativo. Cambiassu - Revista Científica do Departamento de Comunicação Social da Universidade Federal do Maranhão - UFMA, 14, 237-252.

Estelle, B. (2017). The sharing economy : analysing the hype versus the paradigm change in tourism : a case study within the Maltese population. Executive M.B.A. Dissertation - L-Università ta' Malta.

Felson, M. \& Speath, J. (1978). Community structure and collaborative consumption. American Behavioral Scientist, 41, 614-624.

Figueiredo, B., \& Scabaroto, D. (2016). The Systemic Creation of Value Through Circulation in Collaborative Consumer Networks. Journal of Consumer Research, 43(4), 509-533.

Gansky, L. (2010) The Mesh: why the future of Business is Sharing. London: Portfolio/penguim.

Godoi, C. K. (2010). Perspectivas de análise do discurso nos estudos organizacionais. In: Godoi, C. K., BandeiraDe-Mello, R. \& Silva, A. B. Pesquisa Qualitativa em Estudos Organizacionais. 2 ed. São Paulo: Saraiva, 375-402.

Godoi, C. K. \& Mattos, P. L. (2010). Entrevista qualitativa: instrumento de pesquisa e evento dialógico. In: In: Godoi, C. K., Bandeira-De-Mello, R. \& Silva, A. B. Pesquisa Qualitativa em Estudos Organizacionais. 2 ed. São Paulo: Saraiva, 301-324.

Hamari, J. et al. (2015). The Sharing Economy: Why People Participate in Collaborative Consumption. Journal of the Association for Information Science and Technology, 1-28.

Jorge, M. S., Brasil, M. B. \& Ferreira, V. H. (2013). A sociedade em Rede e a perspectiva do consume colaborativo na contemporaneidade. In: $2^{\circ}$ Congresso Internacional de Direito e contemporaneidade, 2013, Santa Maria. Anais... Santa Maria: UFSM, 809-821. 
Korobar, V. (2013). The Interconnection of Sustainability and Collaborative Consumption: A case study of clothing libraries. 2013, 40f. Master's thesis (Programme in Human Ecology).Lund University, Sweden.

Lang, C., \& Armstrong, C. (2018). Collaborative consumption: The influence of fashion leadership, need for uniqueness, and materialism on female consumers' adoption of clothing renting and swapping. Sustainable Production and Consumption, 13, 37-47.

Mattos, P. L. (2005). A Entrevista Não-Estruturada como Forma de Conversação: razões e sugestões para sua análise. Revista de Administração Pública - RAP, Rio de Janeiro, 283-846.

Maurer, A. et al. (2012). Yes, We also Can! O Desenvolvimento de Iniciativas de Consumo Colaborativo no Brasil. In: XXXVI Encontro da ANPAD (EnANPAD), 2012, Rio de Janeiro. Anais... Rio de Janeiro: EnANPAD, 2012, p. 1- 16.

Maya, S. \& Zhai, Y. (2013). Collaborative Consumption Studies in the Less Affluent World: the problematic legacy of the less affluent world traits. Master's thesis (Programme in Human Ecology).Lund University, Sweden.

Merriam, S. B. (1998). Qualitative research and case study applications in education. 2 ed. San Francisco: Jossey-Bass.

Möhlmann, M. (2015). Collaborative consumption: determinants of satisfaction and the likelihood of using a sharing economy option again. Journal of Consumer Behaviour. 14(3), 193-207.

Ozanne, L. K. \& Ballantine, P. W. (2010). Sharing as a form of anti-consumption? An examination of toy library users. Journal of Consumer Behaviour (9)6, 485-498.

P2P Foundation. Synthetic Overview of the Collaborative Economy. 2012. Disponível em: $<$ http://pandodaily.com/collaborative-consumptionis-dead-long-livre-the-real-sharing-economy>. Acesso em: 12 fev. 2015.

Patton, M. Q. (2002). Qualitative research and evaluation methods. 3rd ed. Thousand Oaks, CA: Sage Publications.

Pernambuco, GOVERNO DO ESTADO. (2013). Pernambuco implanta programa de compartilhamento de bicicletas. Secretaria das cidades, maio, 2013. Disponível em:
$<$ http://www2.cidades.pe.gov.br/web/secid/exibir_not icia? groupId $=12855 \&$ articleId $=7016608 \&$ template $I d=15537>$. Acesso em: $17 \mathrm{dez} .2013$.

Pullman, M. \& Gross, M. (2003). Welcome to Your Experience: where you can check out anytime you'd like, but you can never leave. Journal of Business and Management, (9) 3, 215-232.

Rifkin, J. (2000). The Age of Access: The New Culture of Hypercapitalism, Where all of Life is a Paid-For Experience. New York: J.P. Tarcher/Putnam.

Rohden, et al. (2014). Consumo Colaborativo: Economia, Modismo ou Revolução? In: III Congresso Internacional de Pós-Graduações e Pesquisas Latinos em Administração e Estudos Organizacionais, 2014, Porto Alegre. Anais... Porto Alegre: UFRGS, 1-17.

Sachs, I. (2002). Caminhos para o Desenvolvimento Sustentável. Rio de Janeiro: Garamond.

Sastre, P. T. \& Ikeda, A. A. (2012). Reflexões sobre Consumo Colaborativo. In: XXXVI Encontro da ANPAD, 2012, Rio de Janeiro. Anais... Rio de Janeiro: ENANPAD, 1-10.

Scaraboto, D. (2015). Selling, Sharing, and Everything in Between: The Hybrid Economies of Collaborative Networks. Journal of Consumer Research, 42 (1), 156-76.

Silva, M. J. B. \& Barbosa, M. L. (2016). Da posse à possibilidade do acesso? Compreendendo os conceitos de consumo colaborativo no marketing. RIMAR - Revista Interdisciplinar de Marketing (6) 2, 42-53.

Taylor, S. J. \& Bogdan, R. (1998). Introduction to qualitative research methods: a guidebook and resources (3rd ed.). New York: John Wiley \& Sons.

Toni, M., Renzi, M., \& Mattia, G. (2018). Understanding the link between collaborative economy and sustainable behaviour: $\mathrm{Na}$ empirical investigation. Journal of Cleaner Production, 172(20), 4467-4477.

Vaquero, A. L. C \& Calle, P. C. (2013). The Collaborative Consumption: A Form Of Consumption Adapted To Modern Times. Revista de Estudios Económicos y Empresariales, 25, 15-30.

Waes, A., Farla, J., Frenken, K., Jong, J., \& Raven, R. (2018). Business model innovation and sociotechnical transitions. A new prospective framework with an application to bike sharing. Journal of Cleaner Production, 195, 1300-1312.

\title{
Sharing Bicycles and Consuming Experiences: An investigation of the collaborative consumption practiced by Bike-PE users
}

\begin{abstract}
The Collaborative Consumption is a new configuration of consumption practiced thanks to the digital technologies and the possibility of access that these provide. This article analyzes this practice, adopting as a research locus the Bike PE System, a bicycle sharing initiative in operation in the cities of Recife, Jaboatão
\end{abstract}


dos Guararapes and Olinda. From observations and individual interviews with users of this service, it was possible to observe that the consumers of Bike PE have different objectives in the use of the system and experience several problems in the access, use and return of the bicycles, but they remain using the Bike PE due to the advantages of a collaborative practice that brings collective and individual benefits, such as the low cost to use the bicycle, the use without worry about maintenance and safety, the feeling of belonging to society, the possibility of collective conscience, sustainability, health and, especially, the option of use without the need of acquisition.

Keywords: Experience, Collaborative Consumption, Bike PE. 